\title{
DESENVOLVIMENTO DE MUDAS DE MARACUJAZEIRO PROPAGADAS POR ENXERTIA ${ }^{1}$
}

\author{
JANAINA BATISTA LENZA², JOÃO PEDRO VALENTE ${ }^{3}$ \\ GIVANILDO RONCATTO ${ }^{4}$, JOADIL ALVES DE ABREU ${ }^{5}$
}

RESUMO-O objetivo deste trabalho foi avaliar o desenvolvimento de mudas de maracujazeiro-amarelo 'FB 200' enxertadas em seis espécies e nela mesma como porta-enxerto. O trabalho foi desenvolvido na Fazenda Experimental da FAMEV/UFMT entre fevereiro e junho de 2006. O método de enxertia utilizado foi fenda cheia, realizada acima da terceira folha e a uma altura variando de 15 a $30 \mathrm{~cm}$, dependendo do porta-enxerto. As espécies utilizadas como porta-enxerto foram: Passiflora edulis, P. quadrangularis, P. giberti, P. alata, P. nitida, P. coccinea e a 'FB 200', e como enxerto, a variedade FB 200. O desenvolvimento das plantas foi avaliado pelo critério de mensuração da altura e diâmetro, utilizando-se de fita métrica e paquímetro, respectivamente, e pela contagem do número de folhas e de entrenós, realizada aos 60; 75; 90; 105 e 120 dias após a enxertia. As mudas de 'FB 200' apresentam maior desenvolvimento nas condições da Depressão Cuiabana-MT, quando enxertada nos porta-enxertos Passiflora edulis e nele mesmo. Grande dificuldade encontrada para a produção de mudas de maracujazeiros, utilizando-se das espécies $P$. giberti, P. coccinea e P. nitida como porta-enxerto, é o pequeno e lento desenvolvimento do diâmetro do caule.

Termos para indexação: altura, diâmetro, porta-enxerto, número de folhas, número de entrenós.

\section{PASSION FRUIT TREE SEEDLINGS DEVELOPMENT PROPAGATED BY GRAFTING}

\begin{abstract}
The objective of this work was to evaluate the seedlings development of yellow passion fruit tree ' FB200' grafted in six species and in the plant itself as a rootstock. The work was developed on the Experimental Farm of the FAMEV/UFMT between February and June /2006. The used method of grafting was the type full cleft grafting, carried out above the third leaf and to a changeable height depending on the species (from 15 to $30 \mathrm{~cm}$ of height). The species used as a rootstock were: Passiflora edulis, $P$. quadrangularis, P. giberti, P. alata, P. coccinea, P. nitida and the variety FB 200; and as grafting 'FB200'. The following characteristics had been evaluated to measure the development of the plants: height, diameter, number of leaves and internodes, in a period of 60, 75, 90,105 and 120 days after the grafting. The seedlings of variety FB200 produced through the method of grafting for full cleft grafting presented a satisfactory development in the conditions of the Cuiabana-MT Depression, when grafted in the rootstock Passiflora edulis and 'FB200'. A great difficulty for the production of passion fruit tree seedlings by using the species P. giberti, P. coccinea and P. nitida as a rootstock is the small and slow development of the stalk diameter of these species.
\end{abstract}

Index terms: leaf height, diameter, rootstock, leaf number, number of internodes.

\section{INTRODUÇÃO}

O maracujazeiro é uma cultura típica de países tropicais, sendo o Brasil responsável por cerca de $90 \%$ da produção mundial com meio milhão de toneladas de frutas produzidas, destacando-se como uma das principais frutíferas cultivadas no País (Silva et al., 2005). O maracujazeiro-amarelo (P. edulis f. flavicarpa Degener) é a espécie de maior represen- tatividade nos cultivos de Passifloraceas, com 95\% da área plantada (IBGE, 2007). O maracujazeiroamarelo tem maior importância devido à qualidade dos frutos, à divulgação junto aos consumidores e à preferência da agroindústria. Comercialmente, o maracujazeiro é propagado via sexuada, porém este tipo de reprodução encontra sérios problemas devido a pragas e doenças que atacam esta cultura.

A propagação vegetativa do maracujazeiro

\footnotetext{
'(Trabalho 146-08). Recebido em: 09-06-2008. Aceito para publicação em: 25-09-2009.

${ }^{2}$ MsC. Docente da Faculdade de Ciências Agrárias - UNIC. Avenida Beira Rio, 3100 - CEP 78.065-700 E-mail: janainalenza@unic.edu.br ${ }^{3}$ Dr.Docente do Depto. de Fitotecnia e Fitossanidade - UFMT. Av. Fernando Correa da Costa, 2367, Boa Esperança, CEP 78060900 Cuiabá-MT. E-mail: jdfac@terra.com.br

${ }^{4}$ Dr. Pesquisador A da Embrapa Acre. Rodovia BR 364 km 14, Zona Rural, CEP 69.901-180 Rio Branco-AC. E-mail: givanildo@cpafac.embrapa.br

${ }^{5}$ Dr.Docente do Depto. de Zootecnia e Extensão Rural - UFMT. Av. Fernando Correa da Costa, 2367, Boa Esperança, CEP 78060900 Cuiabá-MT. E-mail: joadil@terra.com.br
} 
permite a obtenção de pomares uniformes, bem como o uso de porta-enxertos resistentes a doenças e que possam induzir altas produtividade (Ruggiero \& Oliveira, 1998; Roncatto et al., 2004; Silva et al., 2005).

Com relação à enxertia, Ruggiero (1991) afirma que os tipos mais usados são fenda cheia e inglês simples, com pegamento superior a $90 \%$, em ambos os processos.

Segundo Chaves et al. (2004), várias espécies de Passiflora nativas apresentam resistência a doenças, mas a utilização destas como porta-enxertos oriundos de sementes tem sido dificultada pelas diferenças de diâmetro entre o porta-enxerto e o enxerto. Para algumas espécies como a $P$. nitida, $P$. alata, $P$. edulis, foram realizadas pesquisas para serem usadas como porta-enxerto; por outro lado, são escassas as informações sobre a utilização de $P$. coccinea, $P$. quadrangularis e $P$. giberti, como porta-enxertos.

O P. nitida apresenta grande potencial para utilização em programas de melhoramento que incluam hibridação interespecífica em virtude de sua rusticidade e resistência a vários patógenos e pragas do maracujazeiro (Menezes et al., 1994; Fischer, 2003; Roncatto et al., 2004). O crescimento e o desenvolvimento de plantas de espécies nativas de maracujazeiro em viveiro ou a campo, quando usadas ou não como porta-enxertos, tem sido satisfatório. $\mathrm{Na}$ enxertia, o resultado esperado para combinações de enxerto e copa geneticamente próximas é superior. Neste sentido, Junqueira et al. (2006) observaram que a $P$. nitida é uma das espécies da família Passifloraceae que apresentam um bom crescimento e desenvolvimento, além de resistência a algumas doenças como a Fusariose, porém produz porta-enxertos com caules finos.Por outro lado, Nogueira Filho et al. (2005), ao trabalhar com materiais genéticos que apresentam diâmetros compatíveis, como P. edulis com garfos da espécie comercial, a 'FB 200', observou bom desenvolvimento, devido à maior uniformidade entre o diâmetro do enxerto e do porta-enxerto. O número de folhas é uma característica que, no maracujazeiro, pode sofrer muitas variações devido a fatores não controlados.

O maracujazeiro-doce ( $P$. alata), apesar da menor representatividade, atinge preços unitários mais expressivos no segmento das frutas frescas (Bernacci et al., 2003). Menezes (1990) e Menezes et al. (1994), trabalhando em Jaboticabal - SP, com enxertia de maracujazeiro-amarelo sobre espécies resistentes à murcha de Fusarium sp., constataram que havia diferença quanto ao pegamento entre as espécies estudadas e que, utilizando porta-enxerto de maracujazeiro-doce, obtiveram 93,7\% de pega- mento.

O objetivo deste trabalho foi avaliar o desenvolvimento de mudas de maracujazeiro-amarelo ' $\mathrm{FB}$ 200’ enxertadas em seis diferentes espécies e nele mesmo como porta-enxerto

\section{MATERIAL E MÉTODOS}

O experimento foi realizado em viveiro telado (50\% de sombra), da Fazenda Experimental da FAMEV/UFMT, entre os meses de fevereiro e junho/2006. A Fazenda está localizada em Santo Antônio do Leverger-MT, situada a 30 km de Cuiabá, na latitude $15^{\circ} 47^{\prime} 11^{\prime}$ 'S, longitude $56^{\circ} 04^{\prime} 17^{\prime}$ ' W e a uma altitude de $140 \mathrm{~m}$. O clima da região é classificado conforme Köeppen, como Aw ou Tropical de Savana, com períodos distintos de secas e chuvas. A temperatura média anual fica em torno de $26^{\circ} \mathrm{C}$, precipitação média de $1.360 \mathrm{~mm}$, umidade relativa do ar de 66\% (Miranda \& Amorim, 2000).

O método de enxertia utilizado foi do tipo fenda cheia, realizada acima da terceira folha, em alturas que variaram de 15 a $30 \mathrm{~cm}$, dependendo da espécie. As espécies utilizadas como porta-enxertos foram: Passiflora edulis (acesso Guiratinga-MT), $P$. quadrangularis (acesso Cuiabá-MT), P. giberti (acesso Jaboticabal-SP), P. alata (acesso Aquidauana-MS), maracujazeiro-amarelo ('FB 200'-Araguari-MG), $P$. nitida (acesso Santa Terezinha-MT), $P$. coccinea (Jaboticabal-SP). Utilizou-se como copa (enxerto) o maracujazeiro-amarelo ('FB200'-Araguari-MG).

A semeadura dos porta-enxertos foi feita em tubetes de plástico $(25 \times 5 \mathrm{~cm})$ com substrato comercial Plantimax ${ }^{@}$ (carvão ativado e casca de pínus), posteriormente transplantadas para saco de polietileno $(20 \mathrm{x} 30 \mathrm{~cm})$, com mistura de solo de superfície, e esterco de curral bem curtido, na proporção de $5,25: 1$. respectivamente, sendo enriquecida com superfosfato simples ( $5 \mathrm{~kg} \mathrm{~m}^{3}$ ). As mudas foram enxertadas entre 30 e 90 dias após a germinação, conforme o desenvolvimento das espécies. A variação do tempo pode ser explicada pelas plântulas demorarem mais ou menos tempo para atingir uma altura definida para enxertia. Sendo assim, a característica determinante foi o diâmetro no ponto de enxertia, aguardando o momento ideal de crescimento para a execução da mesma.

As mudas oriundas de sementes foram decapitadas na altura do ponto de enxertia, que variou de 15 a $30 \mathrm{~cm}$,conforme espécie, pois essa foi a altura em que o diâmetro das plântulas estava mais próximo do ideal. Fez-se uma incisão longitudinal de aproximadamente $2 \mathrm{~cm}$ no topo do porta-enxerto, para inserir o garfo (enxerto). Como enxerto, foram usadas 
plantas jovens de 'FB 200', as quais apresentavam duas a três gemas, e $10 \mathrm{~cm}$ de comprimento. A extremidade distal foi preparada na forma de cunha para possibilitar a inserção da mesma no porta-enxerto.

O local da enxertia foi amarrado com fita plástica transparente (fitilho). Após a enxertia, foi colocado saco plástico transparente buscando formar uma câmara úmida, envolvendo o enxerto, até que se efetivasse o pegamento. O saco plástico foi retirado por volta de 15 a 20 dias após a enxertia.

Após 60 dias, iniciou-se a avaliação do desenvolvimento das mudas através das seguintes características: altura de plantas, altura do enxerto e do porta-enxerto, diâmetro do enxerto e do portaenxerto a $2 \mathrm{~cm}$ abaixo e acima do ponto de enxertia; o número de folhas, número de entrenós do enxerto e do porta-enxerto. As alturas foram medidas utilizando-se de um metro (dobrável). As medidas dos diâmetros foram feitas com paquímetro de 1,0 mm de precisão. Todas as avaliações foram realizadas aos 60; 75; 90; 105 e 120 dias após a enxertia. O delineamento experimental foi o inteiramente casualizado, com sete tratamentos e três repetições,com 15 mudas enxertadas por parcela.

Os dados obtidos foram tabulados e submetidos à análise de variância, pelo teste de média ScottKnott, ao nível de 5\% de probabilidade.

\section{RESULTADOS E DISCUSSÃO}

As médias dos resultados obtidos para as características do desenvolvimento das mudas (Tabela 1), onde os valores referentes à altura total representam a altura da muda, incluindo enxerto e porta-enxerto, os melhores resultados para esta característica foram obtidos com os porta-enxertos $P$ edulis e 'FB 200'. Esses resultados eram esperados, pois trata-se de material genético muito próximo, no caso do $P$. edulis, e o mesmo material, no caso do 'FB 200'. Esse fato explica a pequena diferença em diâmetro e, por consequência, seus efeitos no crescimento das plantas. Os outros porta-enxertos avaliados neste trabalho induziram menor desenvolvimento das mudas quanto à altura total.

O pior desempenho apresentado nas espécies $P$. nitida e $P$. coccinea pode ser atribuído às grandes diferenças nos diâmetros destes porta-enxertos, com o diâmetro do enxerto 'FB 200'. Este fato dificultava a realização da enxertia, consequentemente a união dos tecidos, o que provavelmente induziu a morte de mudas em maior número nestas combinações.

Para mensurar o desenvolvimento das plantas, outras características também são importantes , uma das quais é o diâmetro, apesar de não ter uma relação direta entre elas.

No $P$. edulis, obteve-se a maior altura total, porém apresentou valores intermediários para o diâmetro do porta-enxerto (Tabela 1). Já o diâmetro do enxerto foi superior nessa espécie. Por outro lado, no 'FB 200', que juntamente com $P$. edulis apresentou altura total superior estatisticamente aos demais, diferentemente do mesmo, induziu o maior diâmetro.

Este resultado também foi observado por Nogueira Filho (2005), que relacionou a compatibilidade do diâmetro do porta enxerto/enxerto com o pegamento e o desenvolvimento da muda. Neste estudo, o maior desenvolvimento do porta-enxerto foi obtido quando ele foi enxertado sobre si mesmo, lembrando que o 'FB 200' foi usado como enxerto para todos os materiais avaliados.

Com relação ao diâmetro acima da região enxertada, os materiais que induziram os melhores resultados, em ordem decrescente, foram 'FB 200', $P$. quadrangularis, $P$. alata e $P$. edulis.. Conforme Junqueira et al. (2006), a P. nitida é uma das espécies da família Passifloraceae que apresentam um bom crescimento e desenvolvimento, além de resistência a algumas doenças como a Fusariose, porém produz porta-enxertos com caules finos.

Porém, ao se trabalhar com materiais que apresentam diâmetros menores que $0,33 \mathrm{~cm}$, o que ocorreu neste trabalho no momento da enxertia, tornando-se muito difícil a realização da enxertia com o diâmetro dos garfos da espécie comercial utilizada, já que a média da 'FB 200' foi de $0,40 \mathrm{~cm}$.

Acredita-se que o bom desenvolvimento de algumas espécies/variedade ocorreu devido à maior uniformidade entre o diâmetro do enxerto e do portaenxerto, já que os diâmetros dos materiais usados como porta-enxerto que induziram os melhores resultados, eram bem semelhantes ao do enxerto.

Nas mudas enxertadas na 'FB 200' e P. edulis, constatou-se um número significativamente superior de folhas, 12 e 9, respectivamente, enquanto nos demais porta-enxertos, o número final de folhas variou de 5 a 7 unidades por planta.

O número de folhas é uma característica que, no maracujazeiro, pode sofrer muitas variações devido a fatores não controlados, conforme Nogueira Filho (2005), sendo necessário acrescentar outras características de crescimento e desenvolvimento de plantas, como o número de entrenós, uma vez o número de folhas é igual ao número de nós. Dessa forma, onde são avaliados o número de nós indiretamente, é também avaliado o número de folhas. Os mesmos autores consideram o número de internódios 
como parâmetro mais confiável para se mensurar o desenvolvimento das plantas.

O número de entrenós observados nos portaenxertos e no enxerto não apresentou uma correlação direta. Com os porta-enxertos 'FB 200', P. edulis e $P$. giberti, constatou-se um número superior de entrenós no enxerto em relação aos mesmos, evidenciando potencial positivo de indução de crescimento. $\mathrm{O}$ número de entrenós observados no P. giberti, apesar de ser estatisticamente inferior ao 'FB 200' e P. edulis, não tira o mérito do bom potencial desta espécie para ser utilizada como porta-enxerto, pois trata-se de espécie rústica e resistente a pragas e doenças. Na enxertia, o resultado esperado para combinações de enxerto e copa geneticamente próximas é superior. De acordo com (Menezes, 1990; Menezes et al., 1994), as plantas de $P$. giberti, conhecidas vulgarmente como maracujá-de-veado, são produtivas, rústicas, de fácil adaptação e apresentam resistência à morte prematura de plantas. Nas outras espécies avaliadas, o número de entrenós aos 120 dias era inferior no enxerto em relação aos porta-enxertos mostrando o menor vigor das mudas.

$\mathrm{Na}$ Tabela 2, encontra-se o registro acumulado do número e da porcentagem de mudas que morreram ao longo do período avaliado. Nas mudas em $P$. nitida e em $P$. coccínea, constataram-se as maiores porcentagens de morte $71,11 \%$ e $64,4 \%$, respectivamente. A mortalidade das mudas na espécie $P$. giberti foi de $37,77 \%$, e no $P$. quadrangularis, $31,11 \%$. No P. alata, a mortalidade foi de apenas $2,22 \%$, e nas espécie $P$. edulis e na variedade ' $F B$ 200’ não houve morte de plantas até 120 dias após a enxertia.

Nas plantas mortas, não foi encontrado nenhum agente fitopatogênico, portanto acredita-se que a morte tenha sido causada pela diferença nos diâmetros do enxerto (garfos) e do porta-enxerto, que prejudicaram a união dos vasos e consequentemente a translocação das seivas.

Vale ressaltar que, na última avaliação (Tabela 1 ), as espécies 'FB 200' e $P$. edulis foram as que apresentaram melhores resultados quando avaliadas as características de altura total, altura do enxerto e número de entrenós do enxerto. Com exceção da $P$. giberti, as demais espécies/variedade não induziram diferenças estatisticamente significativas pelo teste de Scott-Knott,ao nível de 5\% de probabilidade, para característica número de entrenós do porta-enxerto.

Nogueira Filho (2003) e Nogueira Filho et al. (2005) avaliaram mudas obtidas por enxertia hipocotiledonar e registraram o pior desenvolvimento em altura e diâmetro na espécie $P$. coccínea. Estes resultados podem ser comparados ao obtido no presente trabalho, onde o desempenho das mudas desta espécie foi inferior em relação às demais.

TABELA 1 - Médias das características do desenvolvimento das espécies / variedade de maracujazeiros utilizados como porta-enxerto para a 'FB 200', até 120 dias.

\begin{tabular}{|c|c|c|c|c|c|c|c|c|}
\hline \multirow{3}{*}{$\begin{array}{l}\text { ESPÉCIES / } \\
\text { VARIEDADE }\end{array}$} & \multicolumn{8}{|c|}{ CARACTERÍSTICAS } \\
\hline & \multicolumn{3}{|c|}{ Altura (m) } & \multicolumn{2}{|c|}{ Diâmetro (cm) } & \multirow{2}{*}{$\begin{array}{l}\text { Número } \\
\text { de folhas }\end{array}$} & \multicolumn{2}{|c|}{ Número de entrenós } \\
\hline & $\begin{array}{l}\text { Porta- } \\
\text { Enxerto }\end{array}$ & Enxerto & Total & $\begin{array}{l}\text { Porta- } \\
\text { enxerto }\end{array}$ & Enxerto & & $\begin{array}{l}\text { Porta- } \\
\text { enxerto }\end{array}$ & Enxerto \\
\hline 1-FB200 & $0,22 \mathrm{a}$ & $0,53 a$ & $0,75 a$ & $0,67 a$ & $0,50 \mathrm{a}$ & $12 \mathrm{a}$ & $10 \mathrm{a}$ & $14 \mathrm{a}$ \\
\hline 2- P. coccinea & $0,18 a$ & $0,21 c$ & $0,39 b$ & $0,46 c$ & $0,32 b$ & $5 b$ & $13 a$ & $7 b$ \\
\hline 3- $P$. giberti & $0,17 \mathrm{a}$ & $0,35 b$ & $0,52 b$ & $0,42 \mathrm{c}$ & $0,35 b$ & $6 b$ & $6 b$ & $8 b$ \\
\hline 4- P. alata & $0,16 a$ & $0,19 c$ & $0,35 b$ & $0,61 b$ & $0,42 \mathrm{a}$ & $4 \mathrm{~b}$ & 9a & $6 b$ \\
\hline 5- P. edulis & $0,24 a$ & $0,65 a$ & $0,89 a$ & $0,54 b$ & $0,42 \mathrm{a}$ & 9a & $11 \mathrm{a}$ & $12 \mathrm{a}$ \\
\hline 6- P.quadrangularis & $0,16 a$ & $0,33 b$ & $0,49 b$ & $0,56 b$ & $0,44 a$ & $7 \mathrm{~b}$ & 10a & $9 b$ \\
\hline 7- P. nitida & $0,19 a$ & $0,18 \mathrm{c}$ & $0,37 b$ & $0,49 c$ & $0,39 b$ & $6 b$ & $11 \mathrm{a}$ & $7 b$ \\
\hline CV (\%) & 22 & 31 & 16 & 10 & 9 & 22 & 15 & 20 \\
\hline
\end{tabular}

*Letras iguais na mesma coluna não diferem entre si, pelo teste de Scott-Knott, ao nível de 5\% de probabilidade. 
TABELA 2 - Número e porcentagem acumulada de morte de um total de 45 mudas das espécies / variedade de maracujazeiros utilizados como porta-enxerto para a 'FB 200', aos 75;90; 105 e 120 dias.

\begin{tabular}{|c|c|c|c|c|c|c|c|c|}
\hline \multirow{2}{*}{$\begin{array}{l}\text { ESPÉCIES / } \\
\text { VARIEDADE }\end{array}$} & \multicolumn{4}{|c|}{ NÚMERO DE MUDAS MORTAS } & \multicolumn{4}{|c|}{$\%$ DE MUDAS MORTAS } \\
\hline & 75 & 90 & 105 & 120 & 75 & 90 & 105 & 120 \\
\hline 1-FB200 & 0 & 0 & 0 & 0 & 0 & 0 & 0 & 0 \\
\hline 2- P. coccinea & 0 & 8 & 25 & 29 & 0 & 17,8 & 55,6 & 64,4 \\
\hline 3- P. giberti & 0 & 0 & 0 & 17 & 0 & 0 & 0 & 37,7 \\
\hline 4- P. alata & 0 & 0 & 0 & 1 & 0 & 0 & 0 & 2,22 \\
\hline 5- P. edulis & 0 & 0 & 0 & 0 & 0 & 0 & 0 & 0 \\
\hline 6- P.quadrangularis & 0 & 0 & 0 & 14 & 0 & 0 & 0 & 31,11 \\
\hline 7- P. nitida & 6 & 12 & 12 & 32 & 13,3 & 26,6 & 26,6 & 71,11 \\
\hline
\end{tabular}

\section{CONCLUSÃO}

Podem-se fazer as seguintes conclusões quando se utilizou como copa o maracujazeiro-amarelo seleção 'FB 200’:

1-As mudas apresentaram maior crescimento quando enxertadas em 'FB 200' e P. edulis.

2-As espécies $P$. coccinea, $P$. nitida e $P$. giberti, quando utilizadas como porta-enxerto, induzem aos menores diâmetros de caule, consequentemente induzindo menor crescimento e maior dificuldade para realizar a enxertia.

\section{REFERÊNCIAS}

BERNACCI, L.C.; MELETTI, L.M.M.; SOARESSCOTT, M.D. Maracujá-doce: o autor, a obra e a data da publicação de Passiflora alata (Passifloraceae). Revista Brasileira de Fruticultura, Jaboticabal, v. 25, n. 2, 2003.

CHAVES, R. da C.; JUNQUEIRA, N.T.V.; MANICA, I.; PEIXOTO, J.R.; PEREIRA, A.V.; FIALHO, J. de F. Enxertia de maracujazeiro-azedo em estacas herbáceas enraizadas de espécies de passifloras nativas. Revista Brasileira de Fruticultura, Jaboticabal, v. 26, n. 1,p. 120-123, 2004.

FISCHER, I.H. Seleção de plantas resistentes e de fungicidas para o controle da "morte prematura" do maracujazeiro, causada por Nectria hematococca e Phytophthora parasitica. 2003. 48f. Dissertação (Mestrado) - Escola Superior de Agricultura Luiz de Queiroz, Universidade de São Paulo, Piracicaba, 2003.
IBGE - Instituto Brasileiro de Geografia e Estatística. Produção Agrícola Municipal. Maracujá. Brasília: Ministério do Planejamento, Orçamento e Gestão, 2007. Disponível em: <http://www.sidra.ibge.gov.br/bda/tabela/protabl. $\operatorname{asp} ? \mathrm{z}=\mathrm{t} \& \mathrm{o}=10 \& \mathrm{i}=\mathrm{P}>$. Acesso em: 19 jan. 2007.

JUNQUEIRA, N.T.V.; LAGE, D.A. da C.; BRAGA, M.F.; PEIXOTO, J.R.; BORGES, T.A.; ANDRADE, S.R.M. de. Reação a doenças e produtividade de um clone de maracujazeiro-azedo propagado por estaquia e enxertia em estacas herbáceas de Passiflora silvestre. Revista Brasileira de Fruticultura, Jaboticabal, v. 28, n. 1, p. 97 - 100, 2006.

MENEZES, J.M.T. Seleção de porta-enxertos tolerantes à morte prematura de plantas para $P$. edulis Sims f. flavicarpa Deg. e comportamento de $P$. nitida H.B.K. na região de Jaboticabal. Jaboticabal, 1990. 73 f. Dissertação (Mestrado em Melhoramento Genético Vegetal) - Faculdade de Ciências Agrárias e Veterinárias, Universidade Estadual Paulista, Jaboticabal, 1990.

MENEZES, J.M.T.; OLIVEIRA, J.C.; RUGGIERO, C.; BANZATO, D.A. Avaliação da taxa de pegamento de enxertos de maracujá-amarelo sobre espécies tolerantes à “morte prematura de plantas”. Científica, São Paulo, v.22, n.1, p.95-104, 1994.

MIRANDA, L.; AMORIM, L. Mato Grosso: atlas geográficos. Cuiabá: Entrelinhas, 2000. 
NOGUEIRA FILHO, G.C. Enxertia hipocotiledonar de maracujazeiro-amarelo em diferentes espécies de passifloras silvestres. 2003. $119 \mathrm{f}$. Tese (Doutorado em Agronomia) - Faculdade de Ciências Agrárias e Veterinárias, Universidade Estadual Paulista, Jaboticabal, 2003.

NOGUEIRA FILHO, G.C.; RONCATTO, G.; RUGGIERO, C.; OLIVEIRA, J.C.; MALHEIROS, E.B. Propagação vegetativa do maracujazeiro-conquista de novas adesões. In: FALEIRO, F.G.; JUNQUEIRA, N.T.V.; BRAGA, M.F. (Eds.). Maracujá: germoplasma e melhoramento genético. Planaltina: Embrapa Cerrados, 2005. p. 340-358.

RONCATTO, G.; OLIVEIRA, J.C.; RUGGIERO, C.; NOGUEIRA FILHO, G.C.; CENTURION, M.A.P.C.; FERREIRA, F.R. Comportamento de maracujazeiros (Passiflora spp.) quanto à morte prematura. Revista Brasileira de Fruticultura, Jaboticabal, v.26, n.3, p.552-554, 2004.
RUGGIERO, C. Enxertia do maracujazeiro. In: SÃO JOSÉ, A.R.; FERREIRA, F.R.; VAZ, R.L. A cultura do maracujá no Brasil. Jaboticabal: FUNEP, p.4360. 1991.

RUGGIERO, C.; OLIVEIRA, J.C. de Enxertia do maracujazeiro. In: SIMPÓSIO SOBRE A CULTURA DO MARACUJAZEIRO, 5., 1998, Jaboticabal. Anais... Jaboticabal: UNESP/FCAV, 1998. p.7092.

SILVA, F.M.; CORREA, L. de S.; BOLIANI, A.C.; SANTOS, P.C. dos. Enxertia de mesa de Passiflora edulis Sims f. flavicarpa Deg. sobre Passiflora alata Curtis, em ambiente de nebulização intermitente. Revista Brasileira de Fruticultura, Jaboticabal, v.27, n.1, p.98, 2005. 